\title{
Few controversies in orthodontics - Evidence based studies
}

\author{
Adarshika Yadav', Rohit Kulshreshtha ${ }^{2, *}$, Pranshu Mathur ${ }^{3}$ \\ ${ }^{1,3}$ PG Student, Dept. Orthodontics \& Dentofacial Orthopedics, Saraswati Dental College and Hospital, Lucknow, Uttar Pradesh, \\ ${ }^{2}$ Senior Lecturer, Dept. Orthodontics \& Dentofacial Orthopedics, Terna Dental College and Hospital, Navi Mumbai, \\ Maharashtra, India
}

\section{*Corresponding Author: Rohit Kulshreshtha}

Email: kulrohit@gmail.com

\begin{abstract}
The diversity of opinions among different authors has brought along a cascade of conflicts which led to the development of a series of controversies in the field of orthodontics. Controversy is a state of prolonged public dispute or debate, usually concerning a matter of opinion. The word was coined from the latin word "controversia", as a composite of controversus- "turned in an opposite direction," from contra - "against" - and versus - "to turn against." In Orthodontics the word "controversy" stands a different meaning. Thus it is important to draw a clear distinction between Controversies and Orthodontic controversies. The aim of this article was too state the latest controversies in orthodontics and along with it provides evidence based studies so as to reach to an amicable conclusion.
\end{abstract}

Keywords: Controversies, Extractions, Evidence based orthodontics.

\section{Introduction}

A 'Controversy' features an active and honest difference of Opinion where as an 'Orthodontic controversy' proves to be different. ${ }^{1}$ They never die, they never fade away; they are immortal. They may seem like a good idea; however, it remains to be seen whether or not it will serve to bring us any closer to the ideal of "evidence-based" orthodontics. A major part of the development of this profession has been based on "trial and error" than deductive research because of which controversies sprung up within the field of orthodontics. $^{2}$ Science of orthodontics has been oriented towards seeking explanations and validation of therapeutic methods rather than toward establishing a basis for objectively assessing the quality or utility of our clinical performance. Thus it's more "Opinion based" rather than Evidence based".

It has traditionally been a specialty in which opinions of leaders were important, to a point that professional groups coalesced around a strong leader. Angle, Begg, Tweed societies still exist where "disagreements are the rule rather than exception". ${ }^{3}$ Interestingly a considerable variety of opinion concerning what constitutes good orthodontics has characterized our profession since its beginnings. No consensus exists today, and some opinions are even mutually exclusive. Consequently adherents of a variety of philosophies, though lacking more objective justification for their value systems, accept it as an "act of faith" and if challenged assume a quasi- religious fervour in defence of their beliefs. "It thus seems that many of our values and hence our decisions are essentially on dogmas". 4

The turn of a new century is a good time to review some of the controversies that are inherent in our profession. Great progress has been made from the early days of Edward H. Angle and Calvin Case up to present day orthodontics. However, many aspects of our profession still remain controversial, and as new modalities develop, so do new controversies. Aesthetics has always been one of the prime goals of orthodontic treatment and new challenges and controversies also exist in this area. Today patients are seeking aesthetic enhancement regardless of the increased risk or cost. Among the most important changes that have been made in our profession and that have benefited our patients greatly are the advancements made in material science, as they have improved both the quality and the outcomes of dental and orthodontic care. Another area of change is related to the projected diversity of patients and their potential of access to dental care in the future.

Orthodontic research often seems to prolong controversy, rather than resolve it as answers are approached obliquely and asymptotically, rather than directly. ${ }^{5}$ Clinical orthodontists with time do practice which becomes routine, standardized and decreasingly introspective. Hence clinical experience along with common sense assumes a more commanding role in decision making. A decision is a conscious intellectual process of choices that results in the acceptance and rejection of alternatives the aim of this article was too state the latest controversies in orthodontics and along with it provide evidence based studies so as to reach to an amicable conclusion.

\section{Tongue-thrust and Open Bite}

Age long controversy what came first the anterior open bite or the tongue thrust? Is Tongue The Culprit? The relationship between form and function of the stomatognathic system has been evaluated by many investigators. It has been suggested that some effects on the surrounding oral environment are because of the size, function and posture of the tongue. However, it has long been debated whether malocclusion would be 
lead by tongue function or it merely adapts to local changes of occlusion. Proffit et $\mathrm{al}^{6}$ considered that the essential etiological factors in the development of malocclusion is the size and dysfunction of the tongue as whereas, others such as Mason et $\mathrm{al}^{7}$ believe that tongue thrust swallowing should be considered a result rather than the cause of malocclusion. Tongue thrust is a defined as a condition in which the tongue makes contact with any teeth anterior to the molars during swallowing.

Tongue thrust is an oral habit pattern related to the persistence of an infantile swallow pattern during childhood and adolescence and thereby produces an open bite and protrusion of the anterior tooth segments. Tulley $^{8}$ (1969) states tongue thrust as the forward movement of the tongue tip between the teeth to meet the lower lip during deglutition and in sounds of speech, so that the tongue becomes interdental. Straub ${ }^{9}$ a dental practitioner distributed a progression of articles in the mid 1960's in which he alluded to tongue glitch as a reason for malocclusion, especially anterior open bite. He portrayed the malfunction as thrusting the tongue against or between the anterior teeth while gulping. He noticed an absence of typical masseter movement and abundance of lip muscle action went with this type of gulping. His decision was that swallowing may cause malocclusion or avoid effective orthodontic treatment, and he prescribed a preparation strategy intended to alter patient's gulping. Straub's perceptions and declarations have given catalyst to an extensive variety of studies, clinical reports and conjecturing. They have likewise energized dental practitioners and discourse clinicians to commit broad time and exertion in endeavors to treat or forestall malocclusions by presenting patients to tongue training regimens. The wonder of which Straub composed is known as tongue thrust, infantile or reverse swallowing and the training procedures are called tongue thrust or myofunctional treatment.

Fletcher ${ }^{10}(1970)$ in his broad survey of the writing, noticed that no reliable example of qualities was available inside and between different groups of patients analyzed as tongue thrust swallowers. Proffit and Norton ${ }^{11}$ (1970) concentrated on the connection between tongue function and oral morphology. They reasoned that there is no proof that in horizontal directions muscular activity during swallowing, talking or other oral functions is identified with arch form at present. Weinberg ${ }^{12}$ (1970) in a broad survey of deglutition notes expressed that the meaning of tongue thrust swallow as a disorder seems sketchy and rectify logical information does not give adequate data to determining typical examples of swallow as they relate with occlusion. He additionally expresses that based on accessible confirmation, malocclusion is identified with factors other than muscle function. Mason and Profitt ${ }^{7}$ (1974) in their introduction of the tongue thrust controversy, depict the different clinical orthodontic ways to deal with patients with malocclusions and tongue thrust. They express that redress of the malocclusion will normally bring about a vanishing of the tongue thrust swallowing design with no specific treatment coordinated at the tongue thrust. Profitt ${ }^{13}$ (1972)-Laboratory studies indicate that individuals who place the tongue tip forward when they swallow do not have more tongue force against teeth than those who keep tongue tip back- in fact, tongue force may be lower.

With good anterior occlusion a tongue thrust swallow is often present in children. The anterior open bite tends to close suddenly after a sucking propensity stops, yet the situation of the tongue between the anterior teeth perseveres for some time as the open bite closes. Until the open bite goes, an anterior seal by the tongue tip remains necessary. The modern viewpoint is, in short, that tongue thrust swallowing is seen primarily in two circumstances: in younger children with reasonably normal occlusion, in whom it represents only a transitional stage in normal physiologic maturation; and in individuals of any age with displaced incisors, in whom it is an adaptation to the space between the teeth. The presence of overjet (often) and anterior open bite (nearly always) conditions a child or adult to place the tongue between the anterior teeth. A tongue thrust swallow therefore should be considered the result of displaced incisors, not the cause. It follows, of course, that correcting the tooth position should cause a change in swallow pattern, and this usually happens. It is neither necessary nor desirable to try to teach the patient to swallow differently before beginning orthodontic treatment. This is not to say that the tongue has no etiologic role in the development of open bite malocclusion.

From equilibrium theory, light but maintained pressure by the tongue against the teeth would be expected to have significant effects. Tongue thrust swallowing simply has too short a duration to have an impact on tooth position. Pressure by the tongue against the teeth during a typical swallow goes on for around 1 second. A normal individual gulps about 800 times per day while conscious yet has only a few swallows per hour while asleep The aggregate every day hence is for the most part under 1000. On the other hand, if a patient has a forward resting posture of the tongue, the duration of this light pressure, could affect tooth position, vertically or horizontally.

The tongue thrusts forward to gain anterior valve function in order to prevent the escape of food or liquids. However, the reverse is not always true. A tongue thrust swallowing is often present in children with good anterior occlusion Tulley ${ }^{14}$ (1970) reported an incidence of $2.7 \%$, while Bell and Hale ${ }^{15}$ found $74 \%$ of children in grades 1 through 3 to be tongue thrusters. It has been shown that higher than normal incidence of tongue thrusting is seen in subjects with open bite or overjet malocclusions. Tongue thrust swallowing has 
been assumed to be a contributing factor in the relapse of treatment results. Many research studies have pointed out that orofacial muscle imbalance and deviated swallowing causes a significant percentage of relapse after orthodontic treatment. Fotis et $\mathrm{al}^{16}(1985)$ observed that a dental relapse as a result of skeletal relapse is seen only in cases in which normal perioral function, including normal lip closure and absence of tongue thrust swallowing has not been established after orthodontic treatment. Ozbek et al ${ }^{17}$ (1985) reported that the tongue may spontaneously position itself closer to the palatal roof in patients with excellent retention of maxillary expansion, thus counteracting buccal pressure.

The effect of tongue thrust on dental and skeletal morphology has been evaluated in several studies. It has been demonstrated that protrusive tongue activity (tongue thrust) during swallowing may cause labial inclination of incisors, open bite and spacing problems in some cases. Overstake ${ }^{18}(1975)$ concluded that there is a functional relationship between deviated swallowing and open bite as well as overjet. However, some authors believe that the total duration of swallowing in a normal subject is too short to produce morphological changes. There is no consensus in growing children about the effect of tongue thrusting on incisor position and the influence is not quite clear. Hanson et $\mathrm{al}^{19}$ (1982) reported that the deleterious forces of the tongue result in excessive eruption of posterior teeth, open bite or overjet. There were no significant differences in overbite, upper incisor inclination, lower incisor inclination, and inter incisal angle between the groups of this study.

\section{Conclusion}

The tongue thrust may have an environmental effect on dentofacial structures. Considering the high incidence of tongue thrust in orthodontic patients, it is suggested that dental practitioners observe patients of all ages and those in all stages of orthodontic treatment for evidence of tongue thrust swallowing. Extensive reviews of the literature show that there is no conclusive relationship between tongue function and anterior open bite.

.018 Versus .022 Slot: The earliest slotted bracket appliances relied on precious metal wires for activation. Gold wires were efficient and resilient in the first standardized slot size: the 0.022 inch. In the 1930's stainless steel alloys were introduced and orthodontists soon replaced gold alloys with cheaper stainless steel wires despite the realization that steel wires were less flexible than the equivalent sizes in gold. With the advent of stainless steel wires, edgewise brackets were redesigned from 0.022 to 0.018 slot. ${ }^{20}$ Clinicians in the 1950 's began employing smaller sized wires in the 0.022 inch slot and "light wire" technique was introduced. The mood was now right for a downsizing of edgewise slot dimension from 0.022 to 0.018 to allow light forces with stainless steel. Some orthodontists switched, some did not! Indeed the slot size dichotomy persists even today. Steiner introduced the $0.457 \mathrm{~mm} \times 0.711 \mathrm{~mm}(0.018$-inch $\times 0.028$-inch $)$ slot for stainless steel wires in lieu of the $0.559 \mathrm{~mm} \times$ $0.711 \mathrm{~mm}(0.022$-inch $\times 0.028$-inch slot for gold alloy wires. ${ }^{21}$ Original intention of 022 slot was not meant for sliding mechanics, (as it is ideally suited) but it was for Torque movement control when $22 \times 28$ gold wires were used (Fig. 1)

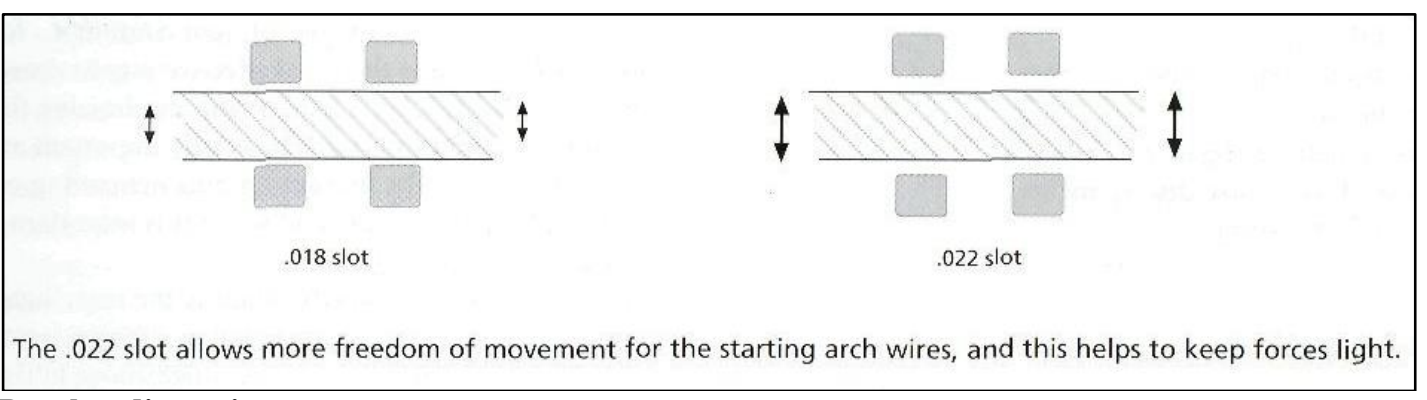

\section{Fig. 1: Bracket dimensions}

0.022 slot however is superior when sliding of teeth is necessary by the use of undersized stiffer wires, but is inferior to 0.018 slot in effective torque expression due to limited springiness and range of stiffer wires used in wider slot. Role of Titanium arch wires became evident in alignment and torque control in wider 022 slot by the characteristics like higher range and resistance to permanent deformation. ${ }^{22}$ Even undersized stiffer wires are the alternate solution. The pre-adjusted appliance seems to perform best in the
0.022 form. The larger slot allows more freedom of movement for the starting wires, and hence helps to keep forces light. Later in treatment, the steel rectangular working wires of $.019 / .025$ have been found to perform well. With the 0.018 slot, the main working wire is normally $.016 / .022$ or $.017 / .025$. These wires are more flexible and hence show greater deflection and binding during space closure with sliding mechanics (Fig. 2). 


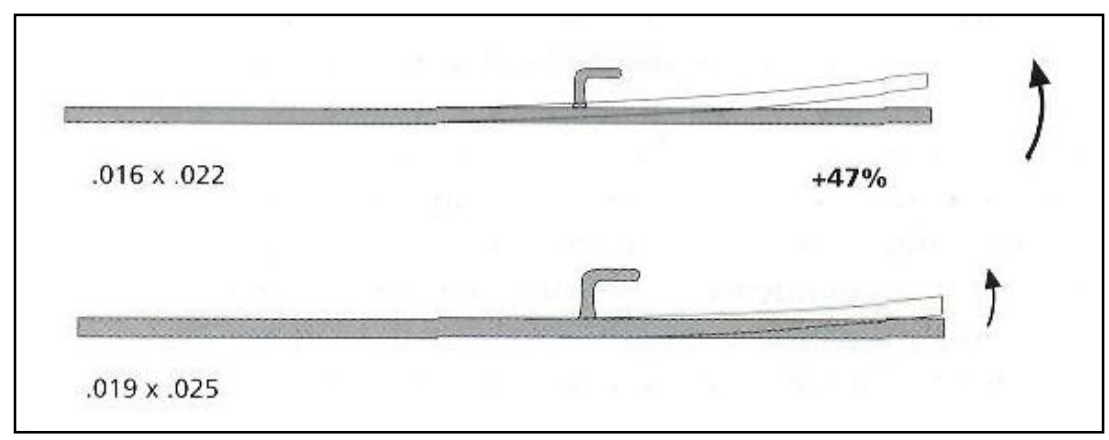

\section{Fig. 2: Wire deflection}

Although there may be fewer choices in arch wire dimensions, filling the bracket slot is more easily accomplished. The capacity to fill the bracket slot allows for a greater use of the program or prescription built into the bracket. This feature provides the advantage of early torque control of anterior teeth. Filling the slot helps in mandibular incisor control. During space closure in the mandibular arch, there is a vector that tends to lingualize the anterior teeth. Filling the bracket slots will preserve the position of these teeth and minimize unwanted lingual crown torque. ${ }^{23}$ Use of a 0.018-inch arch-wire as the widest diameter, thus creating a 0.04-inch clearance in the 0.022-inch canine and premolar brackets. This differential provides free sliding of posterior teeth during space closure. The 0.022 " slot, the slop of $10^{\circ}$ with a $0.019 " \mathrm{x} 0.025^{\prime \prime}$ arch wire must be counteracted by adding torque $\left(10^{\circ}-15^{\circ}\right)$ into the arch wire for utilizing complete built in prescription. ${ }^{24}$

In PEA the 0.022 " slot is preferred because of the following advantages:

1. During levelling and alignment, these slots have definite advantage in choice of alignment wires.

2. 0.022" slots are designed for sliding mechanics which is proven to be more efficient in space closure.

3. As adjunct with PEA, (fixed functional, orthopedic forces, and surgical cases) we require stiff, full size arch wires to avoid deflection. Thus 0.022 " slots are more efficient.

With the use of undersized arch-wires, one can facilitate the free sliding of the arch-wire through the bracket slot. This provides a system with less frictional resistance or binding at the bracket wings. Larger diameter arch-wires for treatment mechanics also has benefits. Larger dimension arch-wires provide increased stiffness and facilitate keeping teeth upright during space closure and retraction mechanics. Conversely, a distinct disadvantage may be encountered when filling the bracket slot. Full-sized stainless steel rectangular archwire become markedly reduced in springiness and range, thereby severely limiting the ability to place effective torque and finishing bends. ${ }^{25}$

Tenbrook $^{26}$ favours and promotes 018 slots in the self ligating system. He explains that 018 slot technique is more efficient because of use of less wire, lower forces, and has more control because the wire/ slot dimension is minimized. This is an advantage, especially in self-ligation. Eric Nease et $\mathrm{al}^{27}$ mentioned that 0.022 " slot with heavy rectangular wires was cumbersome for patients. He used 0.018" slot with 0.017 " wires lighter forces would result in less patient discomfort. Amy Archambault ${ }^{23}$ assessed in fluctuating the slot size of stainless steel orthodontic brackets, the quantitative consequences for torque expression. Clinically successful torque can be accomplished in a 0.022 inch bracket slot with archwire torsion of 15 to 31 degrees for dynamic self-ligating brackets and of 23 to 35 degrees for passive self-ligating brackets with a 0.0190 .025 inch stainless steel wire.

Raymond ${ }^{28}$ used the edgewise bracket slot $(0.018 \mathrm{x}$ $0.030)$ to keep the bracket and wire sizes smaller. The deep slot (0.030) permits two light arches to be employed at once (Base archwire for stabilization \& the auxillary arch or section for rotation or movement). Nonetheless, in our fresh new century, we should try to consolidate the 0.022 -and 0.018 -inch groups into a new slot size standard somewhere between the two standards and with metric dimensions, the undisputed language of science. For example, 0.022 inches .50559 $\mathrm{mm}$ and 0.018 inches $.50457 \mathrm{~mm}$. Why not settle on a single global metric standard slot size of $0.55 \mathrm{~mm}$ (0.02165 inches) or $0.50 \mathrm{~mm}$ (0.01969 inches)? Robert P. Kusy \& John Whitley ${ }^{29}$ (EJO 1999) Smaller brackets requires that the clinician be as much as $25 \%$ more precise in the initial stage or else binding will occur. This outcome suggests that inexperienced clinicians will find the 0.022 " slot more suitable for sliding mechanics. To accomplish that "best case" scenario, most easily within the strength $\&$ stiffness requirements of the appliance, the bracket width \& wire size should be small, \& the bracket slot should be large. All might have turned okay if technology had not made a hair pin bend and come full circle to offer a titanium molybedneum arch wire alloy with a stiffness close to that of gold. As a result of which the world according to its preference split into two United States-0.022" slot and Europe -0.018 "slot. Resolution of the "slot - size" issue would simplify biomaterials \& biomechanics instruction for graduate residents too. 
Christiana Gioka and Theodore Eliades (2004) $)^{30}$ explored in preadjusted appliances, the wellsprings of variety in the outflow of torque. Factors identified with properties of materials were deliberately investigated, including (1) the size distinction of archwires and brackets slot causing the powerlessness to fill the space (2) inconsistencies from the assembling procedure of brackets blocking proper engagement, (3) contrasts in the firmness of wire combinations connected with to the bracket slot, (4) varieties amongst genuine and reported bracket torque values, and (5) ligation modes, all of which may represent expanded third-order clearance or bracket archwire "play". The effect of these variations on the expression of torque is discussed, and the net buccolingual inclinations are provided as a function of wire size and composition for common bracket slotarchwire combinations. Most reports published on this issue indicate a loss of torque control as high as $100 \%$ of the prescribed value. Furthermore, the fallacy of transferring the ideal crown inclination to the torque prescribed in the bracket is illustrated, along with the underestimation of the prescribed torque relative to the proper tooth crown. The realistically required torque is analyzed to its constituent components, involving tooth inclination, compensation for the slot-wire play, and incomplete ligation with elastomeric ligatures. Based on the evidence available, it is proposed that a hightorque prescription should be selected to account for the lack of full expression of the prescribed torque that occurs clinically.

Detterline DA, Isikbay SC, Brizendine EJ, Kula $\mathrm{KS}^{31}(2010)$ determined if there is a significant difference in the clinical outcomes of cases treated with 0.018-inch brackets vs 0.022 -inch brackets according to the American Board of Orthodontics (ABO) Objective Grading System (OGS). Treatment time and the ABOOGS standards in alignment/rotations, marginal ridges, buccolingual inclination, overjet, occlusal relationships, occlusal contacts, inter proximal contacts, and root angulations were used to compare clinical outcomes between a series of 828 consecutively completed orthodontic cases (2005-2008) treated in a university graduate orthodontic clinic with 0.018 -inch- and 0.022 inch-slot brackets. There were statistically, but not clinically, significant differences in treatment times and in total ABO-OGS scores in favor of 0.018-inch brackets as compared with the 0.022 -inch brackets in a university graduate orthodontic clinic (2005-2008).

\section{Conclusion}

Experience with earlier manufacturing advances in other fields shows that the company first to offer a progressive new standard, becomes the "king of the road", miles ahead of the latecomers trying to jump on the bandwagon. With reference to these views of the different authors, I believe that it would have reached the ears of manufacturers too, who might have this "spark" of universal metric system in the pipe line.
Understanding biomechanics is the matter; it is not the slot dimension which in debate.

\section{Temporomandibular Joint Disorders}

Despite many years of basic and clinical research in the field, there is still great controversy regarding the treatment \& management of temporomandibular disorders, and the dental literature is replete with diverse and often diametrically opposed viewpoints on how these conditions should be treated. The major challenge to the clinician dealing with patients having temporomandibular disorders(TMD) is to distinguish between those suffering from masticatory myofascial pain and dysfunction and those who have pathology in the temporomandibular joint. ${ }^{32}$ This is an important distinction because of the different therapeutic approaches that are required in each instance. Much of the difficulty encountered by clinicians in successfully treating TMD patients is based on diagnostic inaccuracy and, therefore, in this issue considerable emphasis has been placed on the proper recognition of the various temporomandibular disorders. ${ }^{33}$

There are still many fallacies that exist in regard to our understanding of the temporomandibular disorders. Temporomandibular disorder (TMD) is generally characterized as an aggregate term that grasps various clinical issues that include the masticatory muscles, the temporomandibular joint (TMJ) and the related structures and structures the most common clinical element harrowing the masticatory apparatus. It is viewed as a musculo-skeletal disorder in this regard. Be that as it may, TMD is additionally the primary driver of torment of non-dental origin in the oro-facial region including head, face and related structures. ${ }^{34}$ Conversely routine orthodontic treatment and many types of dental interventions have been reported as causes of TMD. Right now, orthodontists, dental network and dental patients still civil argument over the conceivable connection between orthodontic treatment and TMD signs and side effects. Michelotti et $\mathrm{al}^{35}$ explored the impacts of an intense occlusal obstruction on habitual muscle movement evaluated in the common habitat, and on signs and symptoms of TMDs. In a double-blind crossover design, an examination was done in which each subject filled in as his / her own control and was checked amid a month and a half, in four distinct conditions: obstruction free condition before the use of any impedance, active obstruction condition, dummy obstruction condition and interference - free condition after the expulsion of the interferences. A portion of gold foil was put on the lower first molar on the occlusal contact to irritate the inter cuspal position. The strip was set on the vestibular surface without meddling with the inter cuspal position to make the dummy obstruction. The movement of the masseter muscle on a similar side to the obstruction side was recorded for eight continuous hours in the 
indigenous habitat by methods for a convenient EMG recorder.

This investigation proved that a reduction in day time constant movement of the masseter muscle was in response of the masticatory framework to dynamic occlusal impedance. None of the subjects reported signs and/or indications of TMD. The lessening may mirror an evasion conduct that the subjects obtained amid their regular diurnal exercises. The expanding pattern of the EMG movement levels demonstrates fast adjustment to the disturbed occlusal condition found after the third account day of the dynamic occlusal impedance condition and is predictable with the steady lessening in the view of occlusal inconvenience. The example examined in this examination included sound subjects without self-report of parafunctional exercises. It is conceivable that the response in patients with TMD to occlusal disturbance is unique. Orthodontists were acquainted with the field of TMD following the theorising of Thompson ${ }^{36}$ who trusted that posterior and superior displacement of the condyle was caused by malocclusion. Consequently, there was the need to present descending and the condyle by freeing up the trapped mandible. From that point, TMD signs or symptoms have relationship with different malocclusion.

Populace construct thinks about were done in light of 3033 subjects to explore the relationship between overbite (vertical occlusal discrepancy) or overjet (sagittal occlusal discrepancy)and self-report of TMD manifestations and the connection between clicking and crepitus of the TMJ, overjet and overbite. 37 Both investigations failed to show a connection between overbite or overjet and TMD signs and symptoms. Posterior cross bite (transversal occlusal disparity) among various malocclusions is thought to strongerly affect the right working of the masticatory framework. A few issues have been credited to the unilateral posterior crossbite. Hesse et $\mathrm{al}^{38}$ prescribed the treatment of posterior crossbite to counteract asymmetrical facial development at a youthful age. Additionally, to keep them from being passed on to the grown-up dentition, early treatment of posterior cross bite is supported. Conversely, where skeletal adjustment has just happened, crossbite orthodontic redress could barely give benefits in grown-ups. At last posterior crossbite may bring about modifications of the disc- condyle relationship, as per the proposed causal chain of events, which in turn are in charge of disc displacement and TMJ clicking. Pullinger et al. ${ }^{39}$ inspected five patient gatherings (i.e. disc displacement with reduction, disc displacement without reduction, TMJ osteoarthrosis with disc displacement history, primary osteoarthritis and myalgia only)in examination with asymptomatic controls and revealed that the possibility of a person with unilateral posterior crossbite having TMJ disc displacement with reduction was 3.3:1. A populace based cross-sectional study ${ }^{122}$ has been done to break down the relationship between TMJ disc displacement and unilateral posterior crossbite. Relapse investigation neglected to locate a critical relationship between unilateral posterior crossbite and disc displacement with reduction in an example of 1291 youthful young people selected from three schools. The authors inferred that atleast in youthful teenagers, unilateral posterior crossbite does not have all the earmarks of being a hazard factor for TMJ clicking and that in any event until youthful preadulthood, there is an underlying ideal TMJ functional adjustment to unilateral posterior crossbite. Albeit no imminent clinical preliminary of this sort of treatment viability has been directed to date, there gives off an impression of being some reason for early revision of unilateral posterior crossbites in kids. In view of these perceptions, clinicians ought to be wary in prescribing early orthodontic treatment pointing just to avert joint clicking, in spite of the fact that there is a method of reasoning for early remedy of unilateral posterior crossbites in kids to enhance neuromuscular capacity of the stomatognathic framework.

Arat et $\mathrm{al}^{40}$ explored condyle-disc positions on sagittal and coronal closed mouth magnetic resonance imaging (MRI) in unilateral and bilateral posterior crossbite patients before and 18 weeks after rapid maxillary expansion (RME). The authors reasoned that RME is neither an anticipation of TMD nor a hazard factor. Moreover, it has been discovered that RME did not change articular disc position and arrangement in youngsters with unilateral posterior crossbite. The proof for causality connecting malocclusion and TMD should regard a few criteria as proposed by Hill in 1965. First of all, the causes (i.e. malocclusions) ought to go before the impacts (i.e. TMDs), though in the writing, we discover considers that demonstrate the inverse [i.e. muscle pain causes changes in the occlusion]. At that point, the affiliation must be solid and the more extreme the malocclusion, the more serious ought to be the ailment. By differentiate, the danger of TMD might be multiplied by only a couple of extreme occlusal factors was recommended by past reports. Furthermore, results from the scientific literature should be consistent across time in the case of evidence of causality. This does not hold for TMD; an expanding number of studies discredit or lessen the significance of the part of occlusal factors in the etiology of TMD, on analyzing the publications from 1995 to 2009. At last, when malocclusion is equally distributed among gender and ages, the real part of impediment additionally seems far-fetched when considering the higher commonness of TMD in females amid their child bearing years. The transcendence of ladies looking for treatment substantially more frequently than man focuses to a conceivable association between estrogen hormones and dysfunction. In such a case, the cause- impact relationship isn't steady with our insight into the systems of the illness is the reason for the idea of 
natural credibility not being fulfilled. It can be inferred that occlusion is presently considered as a cofactor and is at present declining in significance. Other aetiological elements, for example, trauma, parafunctional behaviour, psychosocial disorders, gender, genetics and centrally mediated mechanisms, are viewed as more essential.

\section{Does Orthodontic Treatment Cause TMD?}

The hypothesis has likewise been tried in ongoing decades that diverse orthodontic techniques(e.g. useful apparatuses, class II / III elastics, chin cup, headgear, fixed or removable machines) and treatment designs can be included as aetiological elements for TMD. Dibbets and van der Weele ${ }^{41}$ analyzed gatherings of kids who were treated with various orthodontic treatment methodology, functional appliances, Begg light wire, chin cups, four-first premolars extracted, every other sort of extraction and no extraction. After the beginning of orthodontic treatment, patients were checked for a 20-year time frame. Following 20 years neither orthodontic treatment nor extraction demonstrated a causal association with the signs and symptoms of TMD, in spite of the fact that signs and symptoms of TMD increased with age. In this way, neither orthodontic treatment nor extraction had a causal association with the signs and symptoms of TMD were the conclusion of the authors. Henrikson and Nilner42 looked at 11-15-year-old treated and untreated female subjects with Class II division 1 malocclusions with females with ordinary impediments. Every one of the patients were treated with a fixed apparatus together with either headgear or class II elastics and/or extractions. For a long time, signs and symptoms of TMD were checked. Singular variances of TMD symptoms in each of the three groups were accounted for by the authors. The predominance of TMD symptoms diminished over the 2 years in the orthodontic group. Amid the 2-year time span, the Class II and Normal groups indicated minor changes. Over the 2 years, TMJ clicking expanded in each of the three groups. Thus, the hazard for exacerbating pre-treatment indications of TMD was not expanded by orthodontic treatment. Despite what might be expected, subjects with Class II malocclusions and signs of TMD of muscular origin appeared to benefit practically from orthodontic treatment in a 2 -year viewpoint. Rey et $\mathrm{al}^{43}$ analyzed an example of Class III patients treated with orthodontics and mandibular cervical headgear, Class I patients treated orthodontically without extractions and subjects who had not been already treated for the presence or absence of TMD. They inferred that Class III patients treated with mandibular cervical headgear and fixed appliances for 2-3 years had no more noteworthy pervasiveness of TMD signs and indications than Class I patients treated with fixed appliances or untreated controls. Therefore, treatment- initiated alterations in the TMJ must be deciphered as rebuilding changes.

\section{Influence of Orthognathic Surgery on TMD}

The impact of orthognathic medical procedure (OS) on TMD is another matter of civil argument among orthodontists. A few reports propose that signs and symptoms of TMD might be increased by the surgery; others demonstrate that temporomandibular dysfunction might be started or increased by the surgery. The response to the inquiry whether orthognatic surgery affects the predominance of signs and symptoms of TMDs was the point of a writing survey covering the period from 1966 to 2006. Among 467 articles, three met the consideration criteria. To assess the impacts that OS had on TMD,${ }^{44}$ the logical proof was inadequate. The absence of steady discoveries crosswise over investigations might be credited to various strategies used to survey stomatognathic capacity and dysfunction, the absence of particular assessment of muscular and articular issues, the consideration of various skeletal malocclusions in the examples intriguing model to ponder torment and capacity of the masticatory framework was spoken to by Orthognathic surgery. Tissue harm and inflammatory responses was incited by the surgical approach. Farella et $\mathrm{al}^{45}$ reported that bimaxillary osteotomy did not start or disturb signs and symptoms of TMD and that the event of signs and symptoms of TMD after OS varied with a flighty example examining in a longitudinal report the impacts of an Orthognathic system in a gathering of patients with class III malocclusion on muscular and articular signs and symptoms of TMD.

\section{The Role of Orthodontic Treatment in the Aetiology of TMD}

The part of orthodontic treatment in the cause of TMD isn't affirmed by current information. The conclusions recorded by McNamara et al. are as yet legitimate. Conventional orthodontic treatment, including Begg apparatus, Herbst appliance, Class II elastics and extraction, bionator and headgear, face mask and chin cup, expanded the pervasiveness of TMD was not revealed in any investigation in a metaexamination on orthodontics and TMD. Similar conclusions that neither static nor dynamic occlusal factors (including orthodontics) can be said to 'cause' TMD can be drawn from the audits distributed by Luther, ${ }^{46}$ and that TMD couldn't be corresponded to a particular sort of malocclusion, and there was no help for the conviction that orthodontic treatment may cause TMD was distributed by Mohlin $^{47}$ in methodical survey.

TMD is a multifactorial pathology. Orofacial pain and TMD require a far reaching group approach. It is critical to discount before researching the teeth as the potential aetiological factor, alternate reasons for facial 
pain. As per evidence based dentistry, when settling on choices about the treatment of every patient, dental professionals should utilize current best proof incorporating individual clinical skill with the best accessible clinical confirmation. Faced with a variety of imaging techniques, the clinician needs to decide when imaging should be used and the accuracy of the information that the imaging will provide. In addition to accurate diagnosis, having an understanding of the etiology of a condition is helpful in determining therapy. This must be done to address patient inconvenience and get an impediment that is steady, when the treatment convention incorporates a dental intervention. It is essential to hold up under as a top priority that dysfunctional patients have a lower versatile capacity to occlusal changes since they appear to be more cautious on their impediment and are effectively irritated by occlusal instability. ${ }^{48}$ Therefore, as indicated by the principles that permit a 'perfect and stable' result to be accomplished, occlusal and / or orthodontic treatment must be performed. For TMD management, a few helpful conventions have been recommended. These conditions are of particular concern, not only because their presence may require modification in orthodontic treatment, but also because there have been claims that they can be caused by such therapy. Hence, a rational approach to the general management of these conditions is required. A reasonable relationship is hard to set up amongst occlusion and TMD and to know how and when a malocclusion can unbalance the stomatognathic framework. Despite the fact that presently occlusion is viewed as a potential cofactor yet coordinate proof isn't accessible. ${ }^{49}$

\section{Conclusion}

From the outset, it important to draw a clear distinction between controversies and orthodontic controversies. Ordinary controversies feature an active, honest difference of opinion. Affirmative action is controversial, as are taxation and abortion rights. Eventually, however, the Supreme Court or congress or public opinion or the normal process of social evolution will decide things one way or the other and allow us to move on. Scientific - as opposed to socialcontroversies commonly yield to the accumulation of evidence. Scientists are eager to resolve important questions. They seek answers and when they get them, they tend to move on. Scientific controversies, therefore, tend to come and go. The fathers of our specialty were people of considerable scientific achievement and sophistication. Like their medical colleagues, they, too, disagreed on many basic questions. Orthodontic controversies however, have proved to be different. They never die, they never fade away; they are immortal.

\section{References}

1. Jacobson A. Current controversies in orthodontics Birte Melsen. Am J Orthod Dentofacial Orthop. 1992:101;6:572:573

2. Simon PW. Fundamental principles of a systematic diagnosis of dental anomalies, Boston, 1926, Stratford Co.

3. Angle EH. Classification of Malocclusion. The dental cosmos; a monthly record of dental science. 1899;41;248264.

4. Hellman M. Diagnosis in orthodontia and the method I use in practice. Angle Orthod. 1994:13:3-14.

5. Horowitz S, Hixon EH. The nature of orthodontic diagnosis, St. Louis, 1966, The C. V. Mosby Company.

6. Proffit W.R., Norton, L.A. The tongue and oral morphology: influences of activity during speech and swallowing, Speech and the Dentofacial Complex: The State of the Art: Proceedings of the Workshop: Asha Reports 5, Washington, D.C., American Speech and Hearing Association,. 1970;106-115.

7. Mason R.M., Proffit W.R. The tongue thrust controversy: background and recommendations. J Speech Hear Disord. 1974;39:115-132.

8. Tulley WJ. A clinical appraisal of tongue thrusting. Am J Orthod. 1969;55:640-50.

9. Straub W.J. Malfunction of the human tongue, Part I and Part II, Am J Orthod. 1960;46:404-424.

10. Fletcher S.G.: Processes and maturation of mastication and deglutition, Speech and the Dentofacial Complex: The State of the Art: Proceedings of the Workshop; Asha Reports 5, Washington, D.C.: American Speech and Hearing Association, 1970;92-105.

11. Proffit W.R., Norton, L.A. The tongue and oral morphology: influences of activity during speech and swallowing, Speech and the Dentofacial Complex: The State of the Art: Proceedings of the Workshop: Asha Reports 5, Washington, D.C., American Speech and Hearing Association. 1970;106-115.

12. Weinberg S. Deglution: a review of selected topics, Speech and the Dentofacial Complex: The State of the Art: Proceedings of the Workshop: Asha Reports 5, Washington, D.C., American Speech and Hearing Association. 1970;116-131.

13. Proffit W R. lingual pressure patterns in the transition from tongue thrust to adult swallowing. Arch Oral Biol. 1972; 17:555-563.

14. Tulley WJ. Prevention of malocclusion and dentofacial anomalies. Int Dent J. 1973;23:481-8.

15. Bell D, Hale A. Observations of tongue-thrust swallow in preschool children. J Speech Hear Disord. 1963;28:1957.

16. Fotis V, Melsen B, Williams S. Post-treatment changes of skeletal morphology following treatment aimed at restriction of maxillary growth. Am J Orthod. 1985;88:288-96.

17. Ozbek MM, Memikoglu UT, Altug-Atac AT, Lowe AA.: Stability of maxillary expansion and tongue posture. Angle Orthod. 2009;79:214-20.

18. Overstake CP. Investigation of the efficacy of a treatment program for deviant swallowing and allied problems. Int J Oral Myol. 1975;1:87-104.

19. Hanson ML, Andrianopoulos MV. Tongue thrust and malocclusion: a longitudinal study. Int J Orthod. 1982;20:9-18.

20. Andrews, L.F.: The Straight Wire Appliance: Syllabus of philosophy and techniques, 2nd ed., L.F. Andrews Foundation for Orthodontic Education and Research, San Diego, 1975. 
21. Andrews, L.F.: Straight Wire: The Concept and Appliance, L.A. Wells Co., San Diego, 1999.

22. John Q. Whitley and Robert P. Kusy: Influence of interbracket distances on the resistance to sliding of orthodontic appliances. Am J Orthod Dentofacial Orthop. 2007; 132:360-72.

23. Amy Archambaulta, Ryan Lacoursierea, Hisham Badawib, Paul W. Majorc, Jason Careyd, Carlos FloresMir. Torque Expression in Stainless Steel! Orthodontic Brackets A Systematic Review: Angle Orthod. 2010;80:201-210.

24. Sebanc J, Brantley WA, Pincsak JJ, Conover JP. Variability of effective root torque as a function of edge bevel on orthodontic arch wires. Am J Orthod. 1984;86:43-51.

25. Martin B. Epstein: Benefits and Rationale of Differential Bracket Slot Sizes: The Use of 0.018 Inch and 0.022-Inch Slot Sizes within a Single Bracket. Angle Orthodontist. 2002;72(1).

26. James Tenbro. the great debate: .018 vs .022 april 2011, ortho classic catalog, volume 6 .

27. Eric Ray Nease: 0.018 " versus 0.022 " slot orthodontic brackets: A comparative analysis: Am J Orthod Dentofacial Orthop. 2000;117(2):A1.

28. Raymond E. Siatkowski: Loss of Anterior Torque Control Due to Variations in Bracket Slot and Archwire Dimensions: J Clinc Orthod. 1999;33:9:508-510.

29. Robert P. Kusy \& John Whitley: Influence of archwire and bracket dimensions on sliding mechanics: derivations and determinations of the critical contact angles for binding. Eur J Orthod. 1991:21;199-208.

30. Christiana Gioka, and Theodore Eliades: Materialsinduced variation in the torque expression of preadjusted appliances. Am J Orthod Dentofacial Orthop. 2004;125:323-8.

31. Detterline DA, Isikbay SC, Brizendine EJ, Kula KS: Clinical outcomes of 0.018-inch and 0.022-inch bracket slot using the $\mathrm{ABO}$ objective grading system. Angle Orthod. 2010;80(3):528-32.

32. Laskin .M: The Clinical Diagnosis of Temporomandibular Disorders in the Orthodontic Patient. Seminars in Orthodontics, 1995;1(4):197-206.

33. Michelotti A. and Iodice G.: The role of orthodontics in temporomandibular disorders. J Oral Rehab. 2010;37:411-429.

34. Greene S C. Etiology of Temporomandibular Disorders. Seminars in Orthodontics. 1995;1(4):222-228.

35. Michelotti A, Farella M, Gallo LM, Veltri A, Palla S, Martina R. Effect of occlusal interferences on habitual activity of human masseter. J Dent Res. 2005;84:644648.

36. Thompson JR. Temporomandibular disorders: diagnosis and treatment. In: Sarnat BG, ed. The temporontandibular joint. 2nd edn. Springfield, IL: Charles C Thomas. 1964:146-184.

37. O’Byrn BL, Sadowsky C, Schneider B, BeGole EA. Evaluation of mandibular asymmetry in adults with unilateral posterior Crossbite. Am J Orthod Dentofacial Orthop. 1995;107:394-400.

38. Hesse KL, Artun J, Joondeph DR, Kennedy DB. Changes in condylar position and occlusion associated with maxillary expansion for correction of functional unilateral posterior crossbite. Am J Orthod Dentofacial Orthop. 1997;111:410- 418 .

39. Pullinger AG, Seligman DA, Gornbein JA. A multiple logistic regression analysis of the risk and relative odds of temporomandibular disorders as a function of common occlusal features. J Dent Res. 1993;72:968-979.
40. Arat FE, Arat ZM, Tompson B, Tanju S. Muscular and condylar response to rapid maxillary expansion. Part 3: magnetic resonance assessment of condyle-disc relationship. Am J Orthod Dentofacial Orthop. 2008;133:830-836.

41. Dibbets JM, van der Weele LT. Long-term effects of orthodontic treatment, including extraction, on signs and symptoms attributed to CMD. Eur J Orthod. 1992;14:1620.

42. Henrikson T, Nilner M. Temporomandibular disorders and the need for stomatognathic treatment in orthodontically treated and untreated girls. Eur J Orthod. 2000;22:283-292.

43. Rey D, Oberti G, Baccetti T. Evaluation of temporomandibular disorders in Class III patients treated with mandibular cervical headgear and fixed appliances. Am J Orthod Dentofacial Orthop. 2008;133:379-381.

44. Abrahamsson C, Ekberg EK, Henrikson T, Bondemark L. Alterations of temporomandibular disorders before and after orthognatic surgery. Angle Orthod. 2007;77:729734.

45. Farella M, Michelotti A, Bocchino T, Cimino R, Laino A, Steenks MH. Effects of orthognathic surgery for class III malocclusion on signs and symptoms of temporomandibular disorders and on pressure pain thresholds of the jaw muscles. Int J Oral Maxillofac Surg. 2007;36:583-587.

46. Luther F. TMD and occlusion part II. Damned if we don't? Functional occlusal problems: TMD epidemiology in a wider context. Br Dent J. 2007;13:210-216.

47. Mohlin B, Axelsson S, Paulin G, Pietila“ T, Bondemark $\mathrm{L}$, Brattstro $" \mathrm{~m} \mathrm{~V}$ et al. TMD in relation to malocclusion and orthodontic treatment. Angle Orthod. 2007;77:542548.

48. Macfarlane T, Kenealy P, Kingdon A, Mohlin B, Pilley $\mathrm{R}$, Richmond $\mathrm{S}$ et al. Twenty-year cohort study of health gain from orthodontic treatment: temporomandibular disorders. Am J Orthod Dentofacial Orthop. 2009; 135:692.

49. Kim MR, Graber TM, Viana MA. Orthodontics and temporomandibular disorder: a meta-analysis. Am J Orthod Dentofacial Orthop. 2002;121:438-446. 